\title{
Molecular Epidemiology and Evolution of Avian Infectious Bronchitis Virus
}

Workshop: Infectious Bronchitis (IB) in the Brazilian Poultry Industry

\section{Author(s)}

Montassier HJ

Laboratory of Immunology and Virology Department of Veterinary Pathology

Faculdade de Ciências Agrárias e Veterinárias UNESP - Campus de Jaboticabal

\section{Mail Address}

Helio José Montassier

Laboratory of Immunology and Virology

Department of Veterinary Pathology

Faculdade de Ciências Agrárias e Veterinárias

UNESP - Campus de Jaboticabal

14.884-900. Jaboticabal, SP, Brazil

Telephone: 55-16-3209-2652

Fax: 55-16-3202-4275

E-mail: heliojm@fcav.unesp.br

\section{ABSTRACT}

Mutation and recombination processes are involved in the genetic and phenotypic variations of RNA viruses, leading to the emergence of new variant strains, and give rise to virus population diversity to be modeled by the host, particularly by the immune system, as occurred with infectious bronchitis virus (IBV) in chickens. The consequence is a continuous emergence of new IBV variants with regard to pathotypes, serotypes, and protectotypes. Nucleotide sequencing and subsequent genetic analysis of the $\mathrm{S} 1$ and $\mathrm{N}$ protein gene sequences provide a fast and accurate method to classify and predict IBV genotype, and a powerful instrument to monitor phylogenetic and epidemiological evolution of IBV variants. Despite the use of vaccination programmes, infectious bronchitis has become a serious problem in Brazil. Thus, a significant number of IBV field variants have been identified circulating in the Brazilian commercial poultries between 2000 to 2006 and more recently in Argentina. These viruses seem to be indigenous, because they demonstrated a low genetic relatedness with the majority of the reference strains from North America, Europe and Asia, but were moderately to highly related one to another. In summary, indigenous field IBV variants were evolving and circulating in the field in Brazil and Argentina, and should be considered as initial candidates for protection against current IBV infectious in chickens. However, in vitro and in vivo studies are needed to determine the pathogenicity and immunogenecity of these new isolates, before defining a new vaccine strain.

\section{INTRODUCTION}

Coronaviruses cause a variety of diseases ranging from bronchitis to gastroenteritis, hepatitis, infectious peritonitis, nephritis, and encephalitis both in mammals and birds (Pratelli, 2006). The infectious bronchitis virus (IBV) is, by definition, a coronavirus of domestic fowl (Gallus gallus). Although this virus does indeed cause respiratory disease, there are strains that replicate in many non-respiratory epithelial cells, where they may cause pathologies (e.g. kidney, genital tract), while others replicate on enteric surfaces and result in faecal excretion of the virus (Cavanagh, 2007), despite not normally producing clinical disease

Collectively, the pathological effects of IBV make it one of the most important single causes of infectious disease-related economic loss in poultry production (Cavanagh, 2007). Its distribution is virtually global. First described in the 1930s in the USA, IB importance of IBV has been driven by the extensive genetic variation related to the surface spike (S) protein gene, recognized half a century ago as able of generating extensive antigenic variation. These changes include deletions, insertions, point mutations and, in some cases, recombination. These genetic variations occur continuously in nature and lead to the emergence of 
multiple phenotypes in terms of pathotypes and immuno-types (Figure 1) (Cavanagh \& Naqi 2003). Specifically, virus neutralization tests revealed the existence of a number of serotypes, which are poorly cross-protective (Cavanagh, 2007).

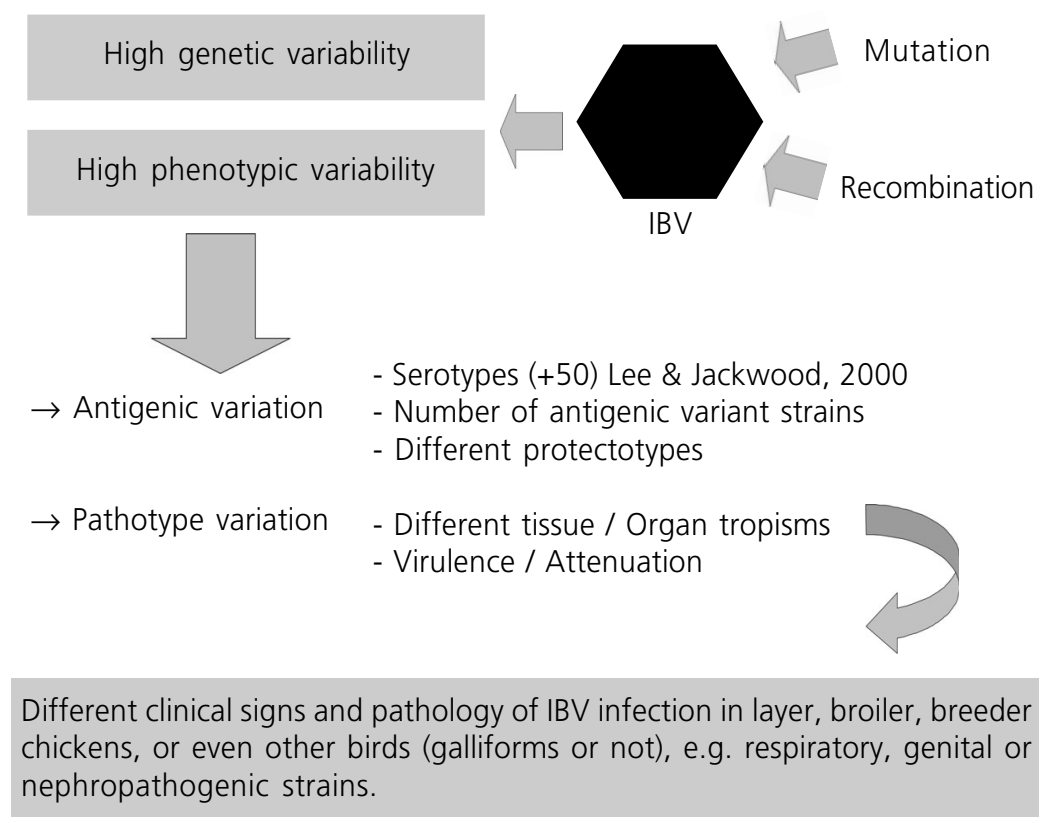

Figure 1 - Genetic and phenotypic variations are common features in the evolution process of infectious bronchitis virus strains and lead to important antigenic and pathotype variability.

Coronaviruses have been classified into three groups, and IBV, together with turkey (TCOV), pheasant (PhCoV), goose (GCoV), duck (DCoV), and

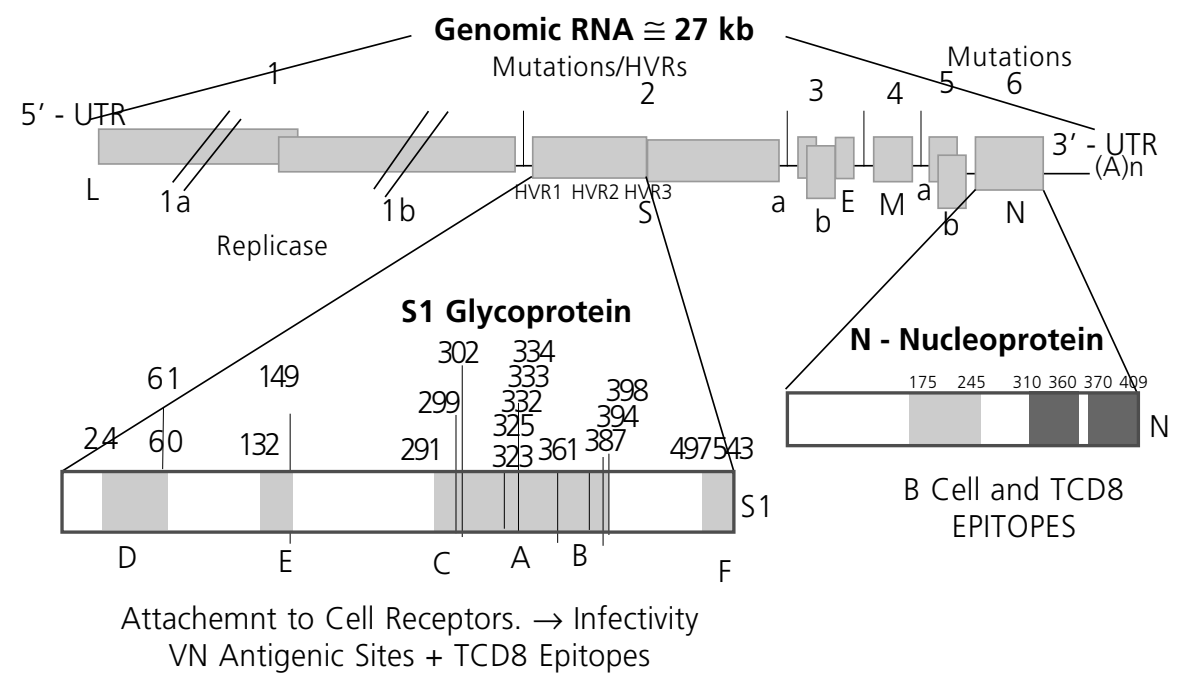

Figure $\mathbf{2}$ - Genomic organization of IBV with mutation hot spots, their relationships with alterations in viral spike glycoprotein and nucleoprotein and the consequences on relevant biological and immunological properties of IBV. pigeon (PCOV) coronaviruses, and belong to Group 3 of Coronaviridae Family and order Nidovirales (Cavanagh \& Naqi 2003, Cavanagh, 2005). The coronavirus groups were initially established on the basis of lack of antigenic relationship among the different groups, and nucleotide sequencing has largely confirmed these groupings (Masters, 2006).

Central to population genetics is understanding how the five main forces of evolutionary change - mutation, recombination, natural selection, genetic drift, and migration - interact to shape the genetic structure of populations. These same forces are also essential to understand RNA viruses evolution (Moya et al., 2004).

IBV, like many other RNA viruses, as well as the coronaviruses, has a high error rate during the transcription of its genomes (Lai \& Cavanagh, 1997), producing a quasispecies phenomenon, where many different viral genotypes co-circulate in the host, with each virus potentially having different levels of fitness for the host environment (Domingo et al., 1985). In fact, the quasispecies phenomenon has been reported to occur among coronaviruses, and it is considered important for the evolution and persistence of these viruses, because it may favor the emergence of new variants in nature, because it may provide mechanisms for virus-escaping from host immune responses (Rowe et al., 1998, Kiss et al., 2000, Nix et al., 2000) (Figure 2). Thus, IBV is continuously evolving, producing new antigenic and/or pathotype variants (Lee, 2002) (Figures 1 and 3). In order to illustrate the importance and frequency of these phenomena since the first isolation of IBV in the 1930s, over 50 serotypes or variants have been described worldwide since then (Cavanagh \& Naqi, 2003; Lee \& Jackwood, 2000).

\section{GENOMIC STRUCTURE, VIRAL PROTEINS, AND BIOLOGICAL ACTIVITIES OF IBV}

The genome of IBV consists of a $27.6 \mathrm{~kb}$ single stranded positivesense RNA molecule including 7 to 10 open reading frames (ORFs) that encode both structural and non- 


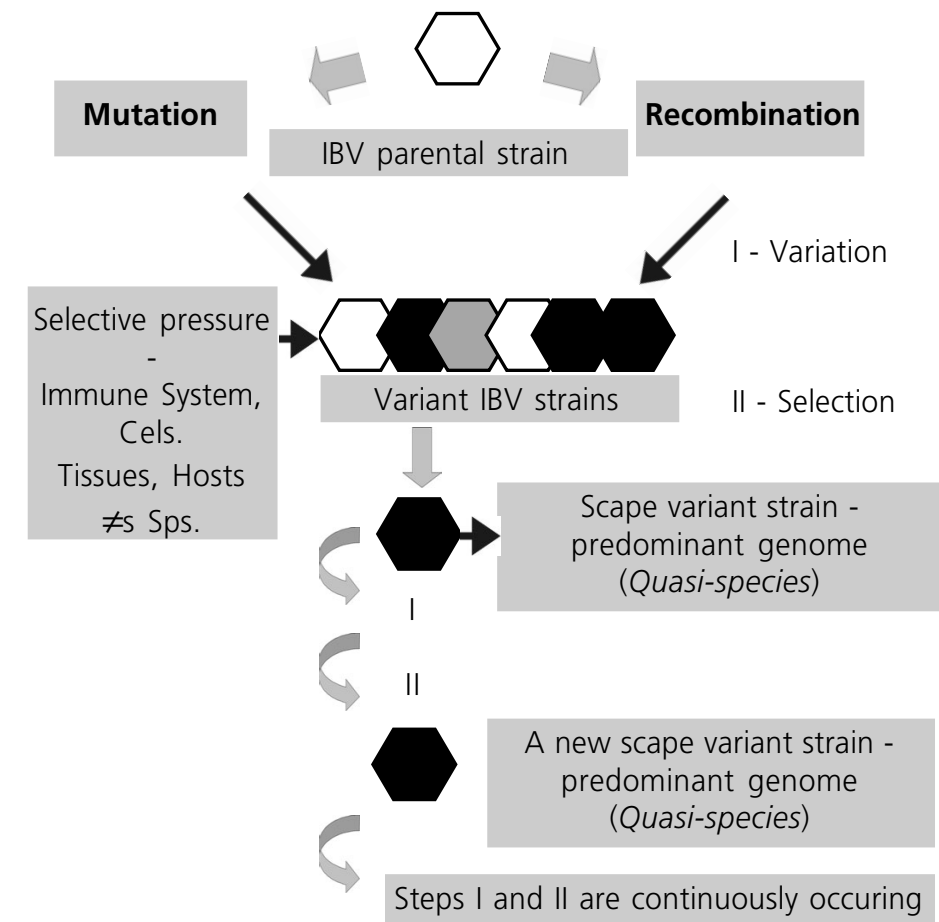

Figure 3 - Role of mutation, recombination and selection in the generation and evolution of quasispecies of IBV strains.

structural viral proteins. Gene 1 consists of two overlapping regions (ORF1a and ORF $1 b$ ) with $20 \mathrm{~kb}$ that are translated into a polyprotein, the precursor of the viral replicase (Rep), which results in 15 non-structural proteins (Nsp2-16). The remainder of the genome encodes four structural proteins: the spike (S) glycoprotein, the small envelope (E) protein, the membrane (M) glycoprotein, and the nucleocapsid $(N)$ protein, as well as five small non-structural accessory proteins: $3 a, 3 b, 3 c, 5 a$, and 5b, which are not required for in-vitro replication, but may play a role in pathogenesis (Casais et al., 2005, Hogson et al., 2006). The genome has the following general organization: 5'UTR - polymerase gene -S-3a,b,c -(E)M-5a,b-N - UTR 3' (Lai \& Cavanagh, 1997, Cavanagh, 2007) (Figure 2).

Gene $S$ consists of one ORF that encodes the spike glycoprotein (S), which is posttranslationally cleaved into the subunits amino-terminal S1 (92-kDa) and carboxyl-terminal S2 (84-kDa), comprising approximately 500 and 600 amino acids, respectively (Cavanagh, 1983; Cavanagh, 2007). In the mature virion, S2 associates with S1, anchoring the S1 protein to the membrane to form the multimeric coiled-coil $\mathrm{S}$ protein (Cavanagh, 2007). Gene N has one ORF, encoding the nucleoprotein, which, together with the genomic RNA, forms the helical nucleocapsid (Collison et al., 1992; Sapats et al., 1996). This protein is highly conserved, differing among distinct IBV isolates by only 2 to $6 \%$ at the amino acid level (Williams et al., 1992).

IBV'S $S$ and N proteins have relevant biological and immunological functions (Figure 2). The $S$ glycoprotein can be divided into three structural domains: a large external domain, which is further divided into two subdomains S1 and S2, a transmembrane domain, and a short carboxyl-terminal domain (Cavanangh, 1983, Lai \& Holmes, 2001). The S1 sequence is more variable, and mutations in this sequence have been associated with altered tissue tropism and antigenicity in IBV strains (Cavanagh \& Naqi, 2003). In fact, the S1 sequences from different strains vary significantly, usually by between 2 and $25 \%$ at the amino level, whereas the S2 subunit is more conserved (Cavanagh et al., 1992, 1997; Kant et al., 1992; Koch et al., 1990). As to its biological properties, the $\mathbf{S 1}$ glycoprotein is the main inducer of virus-neutralizing antibodies, and regulates several other important activities, such as attachment to cells, fusion of the viral envelope with host-cell membranes and, sometimes, cell to cell fusion (Kant et al., 1992, Koch et al., 1990, Lai \& Holmes, 2001) (Figure 2). IBV nucleocapsid protein is a phosphoprotein containing 409 amino acids, and it is well-conserved across various IBV strains (Williams et al., 1992) and important for cell-mediated immunity (Seo \& Collison, 1997, Seo et al., 1997). It forms a protective shell that packages the viral genomic RNA, and it is also thought to participate in viral RNA replication and transcription. Specific packaging of viral genetic material is usually performed via recognition of a particular nucleotide sequence by a nucleocapsid protein (Fan et al., 2005) (Figure 2).

Therefore, variations in $\mathrm{S} 1$ and $\mathrm{N}$ genes, in particular, are believed to be of critical importance for emergence of variants due to their role in virus replication and immunity, and hence $\mathrm{S} 1$ and $\mathrm{N}$ genes and derived proteins are more frequently used to determine the relatedness of emerging IBV.

\section{EVOLUTIONARY CHANGES OF INFECTIOUS BRONCHITIS VIRUS AND THEIR IMPLICATIONS FOR EPIDEMIOLOGY AND CONTROL OF THE DISEASE}

As previously mentioned, IBV infection is worldwide distributed and it is extremely difficult to control because multiple serotypes and variants of the virus are continuously emerging and are not cross protective (Cavanagh \& Naqi, 2003, Cavanagh, 2007). Moreover, coronaviruses, including IBV, have been shown to be a mixture of genetic mutants within an isolate, and 
quasispecies viruses are generated through genetic mutations and recombination events (Domingo et al., 1985; Rowe et al., 1998; Kiss et al., 2000; Nix et al., 2000) (Figures 2 and 3).

Additionally, molecular studies have shown that a new serotype or variant can emerge as a result of only a few changes in the amino acid composition in the S1 part of the virus spike protein, while most of the virus genome remains unchanged (Cavanagh, 2007). This could be due to immunological pressure caused by the widespread use of vaccines, to recombination as a consequence of mixed infections, or to a reduction of dominant serotypes as a result of vaccination, allowing other field strains to emerge (Lee, 2002; Liu et al., 2006) (Figure 4).

The epidemiological investigation of IBV infections has demonstrated that the spreading of a strain from one area or country to another could be due, at least in part, to its improper introduction by the trading of birds, by migratory wild birds, or by the use of attenuated vaccines (Cavanagh, 2005; Liu et al., 2006) (Figure 5A). A very interesting aspect of IBV epidemiology is the presence and dissemination of various IBV serotypes in different continents. A relevant number of emergent serotypes in North America did not spread to other continents, and similarly, European, Australian, and Asian serotypes apparently did not

\section{Infection}

IBV - Parental /

Vacinal Strains

\section{Replication}
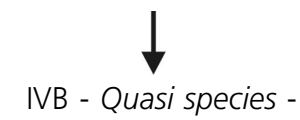

IVB - Quasi species -
Predominant Genome

IBV - Antigenic related to parental / vaccine strains

IBV - Antigenic different from parental / vaccine strains

3. Evolution

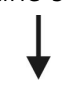

1. Immune pressure by Vaccine

2. Co-infection (recombination)

3. Others constraints (selection botlenecks)

4. Selection

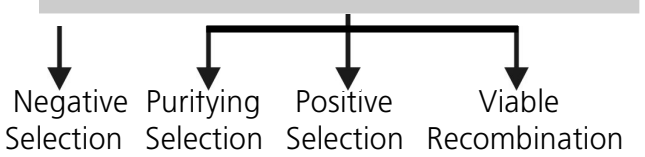

New IBV Variant

Figure 4 - Schematic diagram of the possible evolutionary pathway and emergence of a new antigenic variant (/serotype) from a parental strain of IBV (Adapted from Lee, 2002). spread elsewhere (Liu et al., 2006). However, there are indications that IBVs detected in others countries, such as in China, derive from genetic changes both in IBV populations that existed before vaccination started and in the viruses introduced through live vaccines using attenuated strains from China and other continents, leading to the emergence and co-circulation of strains with various genetic and phenotypic differences (Liu et al., 2006).

A recent review on coronavirus diversity and genomics (Woo et al., 2009) speculated that the ancestor of the present coronaviruses infected a bat, and it jumped from the bat to a bird, or alternatively, it infected a bird and it jumped from the bird to a bat, evolving dichotomously. Or else, the bat coronavirus may have jumped to another bat species, giving rise to group 1 and group 2 coronaviruses, evolving dichotomously. These bat coronaviruses then jumped to other bat species and other mammals, including humans, with each interspecies-jumping evolving dichotomously. On the other hand, bird coronaviruses jumped to other species of birds, and occasionally to some specific mammalian species, with each interspecies-jumping evolving dichotomously, giving rise to group 3 coronaviruses (Woo et al., 2009) (Figure 5B).

IBV evolution is a complex and poorly understood process (Ignjatovic et al., 2006; Vijaykrishna et al., 2007). However, investigations carried out to date highlight the role of three factors: (1) lack of RNA polymerase proofreading, leading to replication errors in RNA genomes with mutation at the order of $10^{-4}$; (2) interference of continuous use of live and often multiple attenuated vaccines formulated with different IBV strains, and (3) immune pressure exerted on circulating viruses by the constant presence of partially immune bird populations. The acquisition of the replicase machinery may have improved the low fidelity of RNA replication to allow genome expansion and give rise to the ancestors of small and, subsequently, large nidoviruses, including the coronaviruses (Gorbalenya et al., 2006).

Genomic alterations affecting coronaviruses probably act in concert and involve point mutations, deletions, insertions, and recombination to generate new virus variants, particularly with regard to $\mathrm{S} 1$ and $\mathrm{N}$ genes (Cavanagh et al, 1992; Ignjatovic, et al., 2006; Jia et al., 1995; Kusters et al., 1990; Lee \& Jackwood, 2000; Wang et al., 1993). Interestingly, evolutionary and mutation rates of IBV isolated from vaccinated birds reached 2.5 and $1.5 \%$ per year, respectively, in the hypervariable regions of the S1 glycoprotein, but, in 


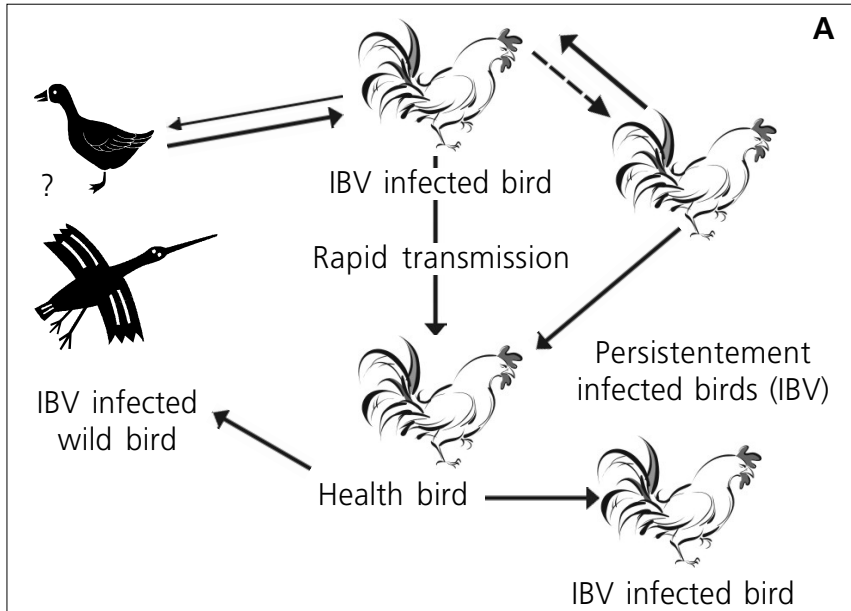

IBV infected bird

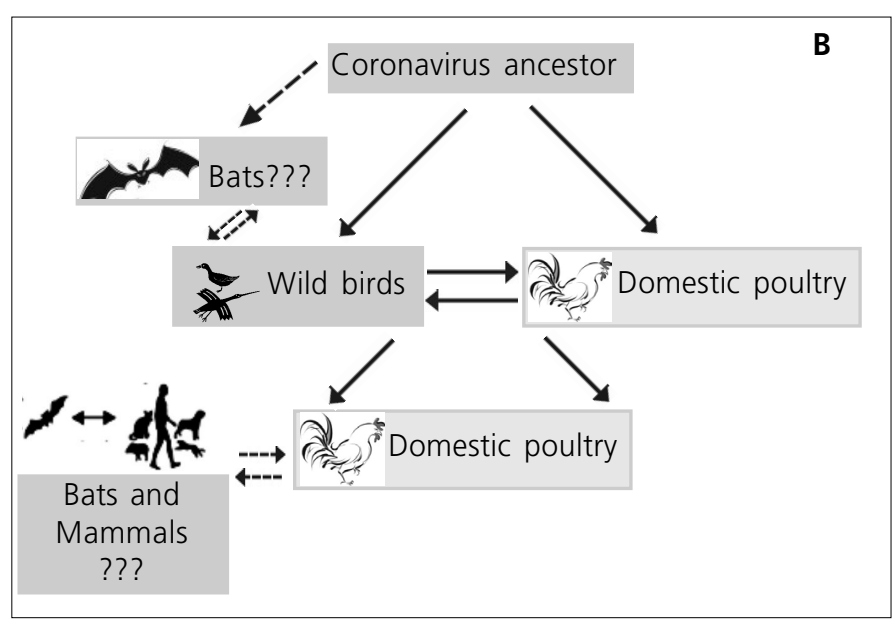

Figure 5 - Proposed epidemiology and transmission of IBV among wild birds and poultry (A). Postulated ecology of Coronaviruses. Hypothetical interspecies transmission and evolutionary pathways. Solid and dashed lines represent confirmed and hypothetical interspecies transmission (B) (Adapted from Woo et al., 2009).

the absence of immunity induced by vaccines, IB viruses evolve at a much slower rate $(0.3 \%$ ) (Lee \& Jackwood, 2001; McKinley et al., 2008) (Table 1).

Table 1 - Comparison of the evolution of two strains of IBV submitted to different immune selective pressures (Adapted from Lee, 2002).

\begin{tabular}{lcc}
\hline IBV Genotype/Serotype & Strains A of IBV & Strain B of IBV \\
\hline Immune pressure & Vaccine use & No vaccination \\
Trend of mutation & Progressive and fixing & Random \\
Mutation rate & $>>(1,5 \% /$ year $)$ & $<<(0,3 \% /$ year $)$ \\
\hline
\end{tabular}

Due to the high variability and important biological properties of the S1 glycoprotein, antigenic evolution in IBV has been primarily associated with changes in the sequence of the S1 glycoprotein, which contains regions associated with virus attachment to cell receptors and relevant epitopes that induce the production of neutralizing antibodies (Cavanagh et al., 1986, 1988). Therefore, different serotypes, subtypes, and antigenic variants of IBV are thought to be generated by nucleotide point mutations, insertions, deletions (Kusters et al., 1987), or RNA recombinations of S1 gene (Jia et al., 1995; Kottier et al., 1995; Wang et al., 1994; Wang \& Huang, 2000), resulting in IB outbreaks even in vaccinated chicken flocks.

In fact, serotypic determinants have been identified in the first 395-amino acid region of the S1 subunit, which contains three major hypervariable regions (HVRs). In the European IBV strains, these HVRs were associated with virus-neutralizing antigenic sites and located between the amino acid residues 56-69 (HVR1), 117-131 (HVR-2), and 274-387 (HVR-3) (Moore et al., 1997; Wang \& Huang, 2000). In addition to the importance of $\mathrm{S} 1$ glycoprotein for immune-protection, the nucleoprotein, particularly its 120 C-terminal residues, contains cytotoxic T-lymphocyte (CTL) epitopes that may reduce viral load and elicit protective immunity by inducing CTL response in chicken hosts (Seo \& Collison, 1997; Seo et al., 1997) (Figure 2).

Therefore, the continuous emergence of new IBV serotypes has hampered the development of appropriate control programs due to antigenic variation and the low degree of cross-protection observed among IBV serotypes (Dolz et al., 2008). This emphasizes the need for prompt and precise diagnosis, mainly to identify new variants of this viral agent and to compare them with the existing vaccine strains (De Wit, 2000). Nucleotide sequencing, followed by phylogenetic analysis of S1 protein gene sequences, offers a rapid and accurate method to identify the IBV genotype, as well as to predict IBV serotype, thereby contributing to evaluate phylogenetic and epidemiological evolution of IBV strains (De Wit, 2000; Lee and Jackwood, 2001; Moore et al., 1997; Wang \& Huang, 2000). It was demonstrated that mutation and recombination processes are involved in IBV genetic variation and subsequent evolution by a mechanism that leads to the emergence of new variant strains and the generation of virus population diversity (Jia et al., 1995; Kottier et al., 1995; Lee \& Jackwood, 2000; Wang et al., 1997) (Figure 3). However, very distinct epidemiological behaviors among these new strains have been described (Figure 5). It is intriguing that some emergent viruses rapidly spread to other geographic areas and become prevalent, whereas others remain restricted to the region of origin. Therefore, monitoring 
IBV subpopulation dynamics in a specific region over time may reveal molecular features that contribute to the different fitting and spreading abilities of IBV strains (Dolz et al., 2008).

Moreover, the effect of recombination on the generation of IBV antigenic variants capable of escaping from the immune responses of the vaccinated chickens can be also mediated by $\mathrm{S} 1$ and $\mathrm{N}$ genes (Figure 6). Considering that the 5 ' region of S1 protein contains most of the neutralizing epitopes (Kant et al., 1992; Koch et al., 1990; Lai \& Holmes, 2001), and that the $3^{\prime}$ region of $N$ protein contains protective $C T L$ epitopes (Seo \& Collison, 1997; Seo et al., 1997) as well as the most immunogenic linear B-cell epitopes (Seah et al., 2000), inter-strain recombination between these genes could act as a relevant mechanism for the generation of genetic and immuno-phenotypic variants that result in the selection of better adapted IBV strains, exhibiting distinct antigen-types, protectotypes, and pathotypes (different tissue tropisms, and increased or reduced virulence). Thus, a successful IBV escape mutant must have altered critical epitopes in these viral proteins, in order to persist, and/ or cause disease in immunized host chickens ( $\mathrm{Yu}$ et al., 2001).

In summary, in the context of viral evolution, recombination is a fast and efficient way to get rid of accumulated deleterious changes in the genome and to create or spread beneficial combinations of mutations in an efficient manner (Lee, 2002) (Figure 6).

\section{MOLECULAR EPIDEMIOLOGY AND EVOLUTION OF IBV IN BRAZIL}

Brazil is currently one of the major poultry-producing countries in the world and in the last few years infectious bronchitis has become a serious problem and is considered endemic. This disease is controlled in Brazil mainly by vaccination using live attenuated or inactivated vaccines mostly based on Massachusetts strain. Neverthless, outbreaks of IB are still occurring in vaccinated flocks, indicating that, most probably, variant isolates of a different serotype to the vaccine strain were emerging.

In 1957 the first isolation of IBV was recorded in Brazil (Hipólito, 1957), and despite the official introduction of IBV vaccination in 1979 with strains H52 and/or H120, outbreaks have continued (Ito, 2006). Apparently, most Brazilian IBV field isolates recovered until 1989 were classified by cross-neutralization test

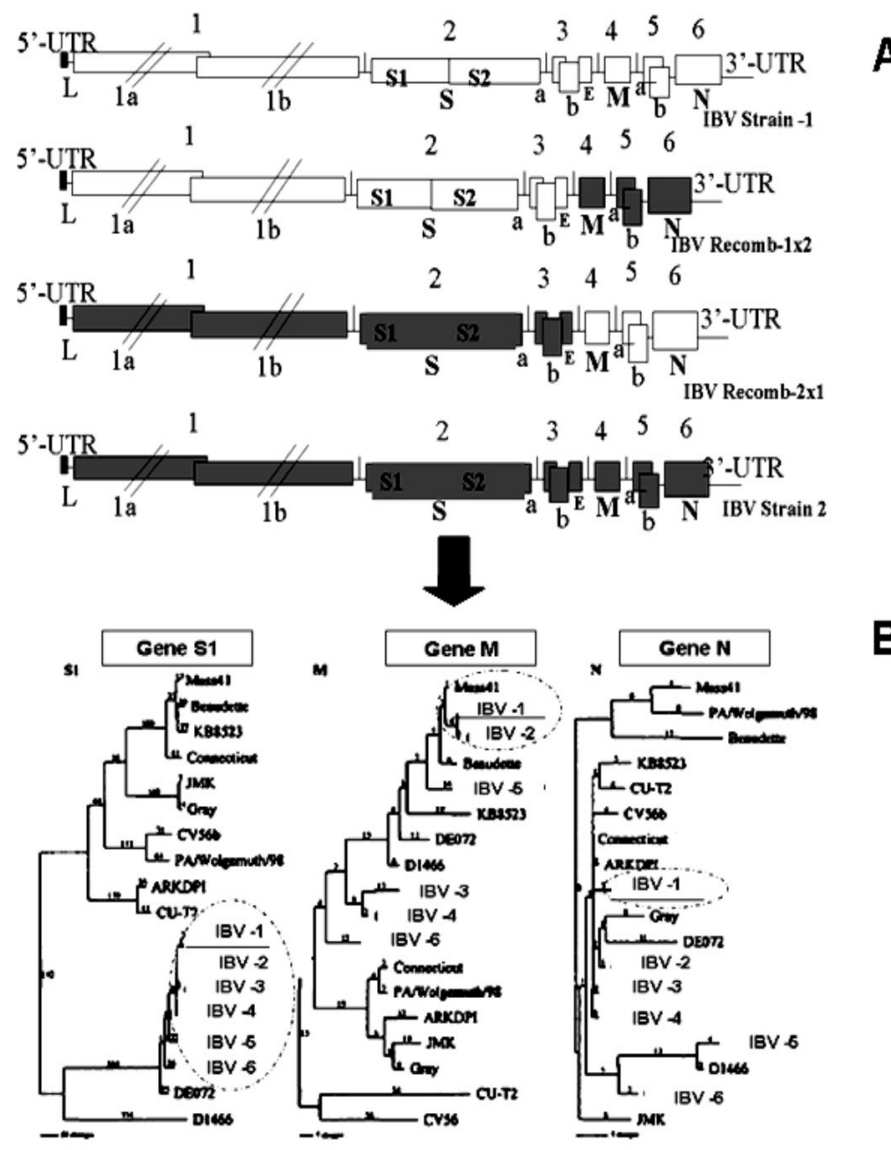

Figure $\mathbf{6}$ - Schematic recombination process at genomic level of two IBV strains ( 1 / "white" genome and 2 / "grey" genome) and the generated recombinant progeny (A). Effects of recombination phenomena among IBV variant isolates (IBV-1; IBV-2; IBV3; IBV-4; IBV-5 and IBV-6) belonging to one serotype, defined by phylogenetic analysis based on nucleotide sequence of S1, M and $\mathrm{N}$ genes. Dashed lines delimited the group of recombinant IBV isolates or the isolate IBV-1 (B).

as Mass serotype (Ito, 2006). Di Fabio et al. (2000) investigated by cross-neutralization tests of tracheal organ cultures a group of 15 IBV field isolates collected in Brazilian commercial flocks, which had experienced a variety of IB-like conditions, including respiratory disease, digestive and kidney problems, and/or drop in egg production. One of the isolates was associated to the Massachusetts (Mass) serotype and the other fourteen were classified in at least four antigenic groups, all distinct from those previously described in other countries.

More recently, a significant number of IBV field isolates, phylogenetically different from patterns of $\mathrm{S} 1$, $\mathrm{N}$, or non-structural protein code genes of American, European, Australian or even Asiatic strains, has been reported Brazilian commercial birds (Abreu et al., 2006; Brentano et al., 2006; Montassier et al., 2006, 2008; 
Villarreal et al., 2007a,b).

Twelve Brazilian IBV field isolates were recovered from different IB outbreaks affecting commercial broiler or layer flocks located in South and Southeast Brazil between 1988 and 2000. These viruses have amplified the S1 gene by RT-PCR and were analyzed by restriction length polymorphism (RFLP) of the entire S1 gene. Additionally, nucleotide sequences of the 5'part of the S1 gene containing $399 \mathrm{bp}$, including hypervariable regions 1 and 2, were also obtained and analyzed in comparison with reference IBV strains, including H120 vaccine strains. The S1 phylogenetic analysis, using either the partial nucleotide or amino acid deduced sequences of these twelve isolates, supported the RFLP findings, based on the use of the enzymes HaellI, Xcml and Bstyl on the entire amplified product of S1 gene and separated these viruses into five genotypes, identified by five clades in the dendrogram. The identity values for the $\mathrm{S} 1$ sequence of the isolates classified by RFLP as Mass genotype along with the $\mathrm{H} 120$ strain, were high and ranged from 96.4 to $100 \%$, characterizing an individualized cluster of these viruses (clade I). There is one isolate with a unique $\mathrm{Xcm} /$-RFLP profile, which displayed lower relationship with Mass genotype and represented a distinct genotype and was classified in a separate branch (clade II). The other six field isolates, identified by Haell-RFLP as three different genotypes, were even less related to the Mass genotype, exhibiting lower identity values to Massachusetts-related strains. However, close relationships were detected for the viruses belonging to each one of the three groups, resulting in the separation by phylogenetic analysis into clade III (Genotype A by RFLP), clade IV (Genotype B by RFLP) and clade V (Genotype C by RFLP) (Montassier et al., 2006, 2008) (Figure 7).

Among the Brazilian IBV variants, and classified more distant to the Massachusetts Genotype, there are two viruses isolated in 1988 and two in 2000 from birds with IB respiratory signs. In an additional phylogenetic analysis, including 5'- S1 gene sequences of reference IBV strains and another set of IB viruses isolated more recent in Brazil (2004 and 2006), these viruses displayed low genetic relationship with most of the reference strains of IBV from North America, Europe and Asia, but exhibited an intermediate to high relationship with the new set of Brazilian isolates recovered between 2004 and 2005 from poultry flocks with enteric and reproductive problems. It is also noteworthy that the viruses isolated earlier, in 1988, were placed, after the phylogenetic analysis, in a branch more distant from
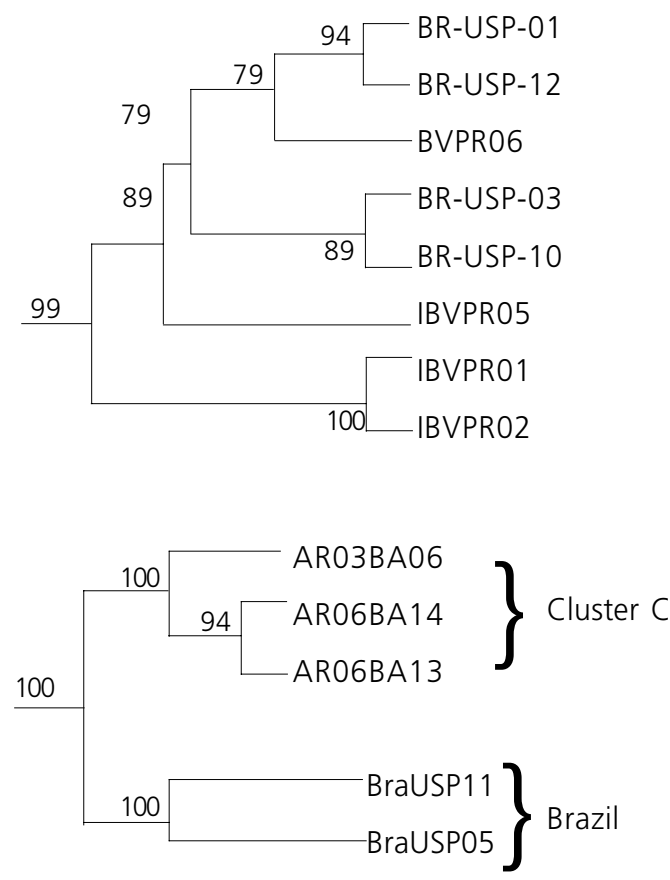

Figure 7 - Dendrograms highlighting a group of indigenous IB viruses isolated from Brazil (IBVPR01, IBVPR02, IBVPR05 and IBVPR06) (Montassier et al., 2006) (A) and Argentine (B) composed by Cluster $C$ derived from phylogenetic analysis of 3 Argentinean and 2 Brazilian IB indigenous variants based on the 5 '- part of S1 glycoprotein gene (nucleotides 685 to 836) (Rimondi et al., 2009). These viruses were moderate to high genetic related one each other ( 86.4 to $99.2 \%$ of identity) and the groups were supported by high bootstrap values (Montassier et al., 2006, Rimondi et al., 2009).

those branches clustering the variant viruses, isolated more recently, in the years of 2000, 2004 and 2005 (Figure 7A). Additionally, two of these new Brazilian variants were clustered together with three Argentinean isolates recovered from broilers and layers during different outbreaks in commercial poultry flocks in different geographic regions of Argentina from 2001 to 2008. All these Argentinean and Brazilian IBV isolates shared $93.4 \%$ of similarity in their amino acid sequences (Rimondi et al., 2009) (Figure 7B). Therefore, these variant viruses seem to be indigenous of Brazil and Argentina, and may share a common ancestor. They are evolving in the field by infecting either vaccinated, or non-vaccinated chickens from commercial poultries in these countries (Figure 8).

To date, the obtained data have also demonstrated that a Brazilian variant genotype has been circulating and evolving in the field since at least as early as 1988 , but there are still few scientific studies on the genetic, antigenic, and pathotype variation of serotypes and dynamics along time of IBV genotypes/phenotypes of 


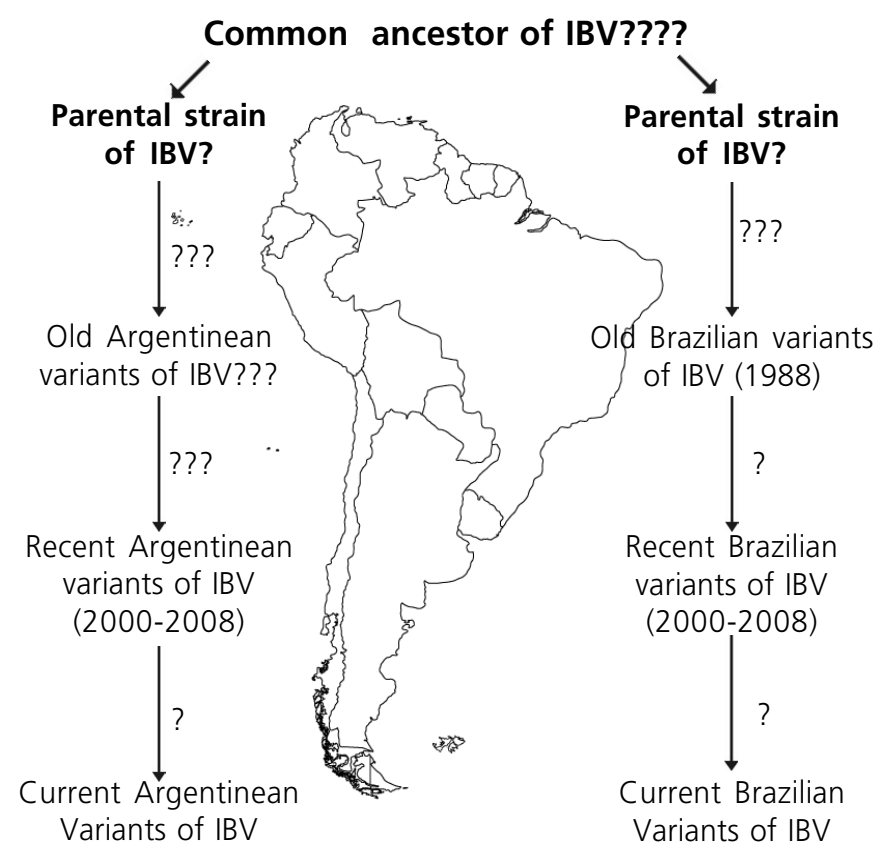

Figure 8 - Hypothetical interactions and evolutionary pathways for new IBV variants from Argentina and Brazil. The possible consequences on immunoprophylaxis scenarios of IBV infection in these countries are presented.

a specific region, and particularly in Brazil. Although these viruses may be the reason of IB frequent outbreaks in that country, it is also essential to determine the immunotypes (serotypes and protectotypes) and the pathotypes (tissue tropism and virulence properties) of these variants in order to fully characterize them. Therefore, the biological and epidemiological behaviors of these variants need to be further studied, contributing to define a more effective programs for IB control, considering that the inefficacy of the current control methods based only on monovalent vaccination with the Massachusetts serotype vaccine is the main issue to be solved.

\section{REFERENCES}

Abreu JT, Resende JS, Flatschart RB, Folgueras-Flatschart AV, Mendes ACR, Martins NRS, Silva CBA, Ferreira MC, Resende M. Molecular Analysis of Brazilian Infectious Bronchitis Field Isolates by Reverse Transcription-Polymerase Chain Reaction, Restriction Fragment Length Polymorphism, and Partial Sequencing of the N Gene. Avian Disease 2006; 50:494-501.

Brentano L, Esteves PA, Trevisol IM, Hayashi MM, Luciano RL, Castro AGM, Klein TAP, Molinari M. Sequenciamento do gene S1 de vírus da bronquite infecciosa de surtos da doença associada a lesões de miopatia peitoral. Brazilian Journal of Poultry Science 2006; Suppl 8:241.
Casais R, Davies M, Cavanagh D, Britton P. Gene 5 of the avian coronavirus infectious bronchitis virus is not essential for replication. Journal of Virology 2005;79:8065-8078.

Cavanagh D. Coronavirus IBV: structural characterization of the spike protein. Journal of General Virology 1983; 64: 2577-2583.

Cavanagh D, Davis PJ. Coronavirus IBV: removal of spike glycopolypeptide $\mathrm{S1}$ by urea abolishes infectivity and haemagglutination but not attachment to cells. Journal of Genetic Virology 1986; 67:1443-1448.

Cavanagh D, Davis PJ, Moc- Kett APA. Amino acids within hypervariable region 1 of avian coronavirus IBV (Massachusetts serotype) spike glycoprotein are associated with neutralization epitopes. Virus Research 1988; 11:141-150.

Cavanagh D, Davis PJ, Cook JKA, Li D, Kant A, Koch G. Location of the amino-acid differences in the $\mathrm{S} 1$ spike glycoprotein subunit of closely related serotypes of infectious-bronchitis virus, Avian Pathology 1992; 21:33-43.

Cavanagh D, Ellis MM, Cook JKA. Relationship between sequence variation in the $\mathrm{S} 1$ spike protein of infectious bronchitis virus and the extent of cross-protection in vivo. Avian Pathology 1997; 26: 63-74.

Cavanagh D, Naqi S. Infectious Bronchitis. In: Calnek BW, Barnes HJ, Beard CW. Diseases of poultry. 11th ed. Ames: lowa State University Press; 2003. p.101-119.

Cavanagh D. Coronaviruses in poultry and other birds. Avian Pathology 2005; 34:439-448.

Cavanagh D. Coronavirus avian infectious bronchitis virus. Veterinary Research 2007; 38:281-297.

Collisson EW, Parr RL, Wang L, Williams AK. An overview of molecular characteristics of avian infectious bronchitis virus. Poultry Science Reviews 1992; 4:41-55.

De Wit JJ. Detection of infectious bronchitis virus. Avian Pathology 2000; 29:71-93.

Di Fabio J, Rossini LI, Orbell SJ, Paul G, Huggins MB, Malo A, Silva BGM, Cook JKA. Characterization of infectious bronchitis viruses isolated from outbreaks of disease in commercial flocks in Brazil. Avian Disease 2000; 44:582-589.

Dolz R, Pujols J, Ordóñez G, Porta R, Majó N. Molecular epidemiology and evolution of avian infectious bronchitis virus in Spain over a fourteen-year period. Virology 2008; 374:50-59.

Domingo E, Martínez-Salas E, Sobrino F, de la Torre JC, Portela A, Ortín J, López-Galindez C, Pérez-Breña P, Villanueva N, Nájera R. The quasispecies (extremely heterogeneous) nature of viral RNA genome population; biological relevance-a review. Gene 1985; 40: 1-8.

Fan H, Ooi A, Tan YW, Wang S, Fang S, Liu DX, Lescar J. The nucleocapsid protein of coronavirus infectious bronchitis virus: crystal structure of its $\mathrm{N}$-terminal domain and multimerization properties. Structure 2005; 13:1859-1868. 
Gorbalenya AE, Enjuanes L, Ziebuhr J,. Snijder EJ. Nidovirales: Evolving the largest RNA virus genome. Virus Research 2006; 117 : 17-37.

Hodgson T, Britton P, Cavanagh D. Neither the RNA nor the proteins of open reading frames $3 a$ and $3 b$ of the coronavirus infectious bronchitis virus are essential for replication. Journal of Virology 2006; 80:296-305.

Ignjatovic J, Gould G, Sapats S. Isolation of a variant infectious bronchitis virus in Australia that further illustrates diversity among emerging strains. Archives of Virology 2006; 151:1567-1585.

Ito NK, Miyaji C, Okabayashi S. Controle de variantes do vírus da bronquite infecciosa das galinhas. Anais da Conferência APINCO; 2006; Santos, São Paulo. Brasil. p.75-99.

JiaW, Karaca K, Parrish CR, Naqi SA. A novel variant of avian infectious bronchitis virus resulting from recombination among three different strains. Archives of Virology 1995; 140:259-271.

Kant A, Koch G, van Roozelaar DJ, Kusters JG, Poelwijk FAJ, van der Zeijst BAM, Location of antigenic sites defined by neutralising monoclonal antibodies on the S1 avian infectious bronchitis virus glycopolypeptide. Journal of General Virology 1992; 73:591-596.

Kiss I, Kecskemeti S, Tanyi J, Klingeborn B, Belak S. Preliminary studies on feline coronavirus distribution in naturally and experimentally infected cats. Research in Veterinary Science 2000; 68:237-242.

Koch G, Hartog L, Kant A, van Roozelaar D J. Antigenic domains of the peplomer protein of avian infectious bronchitis virus: correlation with biological function. Journal of General Virology 1990; 71:1929-1935

Kottier SA, Cavanagh D, Britton P. Experimental evidence of recombination in coronavirus infectious bronchitis virus. Virology 1995; 213:569-580.

Kusters JG, Niesters HGM, Bleumink-Pluym NMC. Molecular epidemiology of infectious bronchitis virus in The Netherlands. Journal of General Virology 1987; 68:343-352.

Kusters JG, Jager EJ, Niesters HGM, van der Zeijst BAM. Sequence evidence for RNA recombination in field isolates of avian coronavirus infectious bronchitis virus. Vaccine 1990; 8:605-608.

Lai MMC, Cavanagh D. The molecular biology of coronaviruses, Advances in Virus Research 1997; 48:1-100.

Lai MMC, Holmes KV. Coronaviridae: the viruses and their replication. In: Knipe DM, Howley PM, Griffin DE, Lamb RA, Martin MA, Roizman B, Strais SE, editors. Fields virology. Philadelphia: Lippincott Williams and Wilkins; 2001. p.1163-1185.

Lee CW, Jackwood M W. Evidence of genetic diversity generated by recombination among avian coronavirus IBV. Archives of Virology 2000; 145:2135-2148.

Lee CW, Jackwood MW. Origin and evolution of Georgia 98 (GA98), a new serotype of avian infectious bronchitis virus. Virus Research
$2001 ; 80: 33-39$

Lee CW. Evolution of avian infectious bronchitis virus: genetic drift and recombination. Korean Journal of Veterinary Service 2002; 25:97-103.

Liu, S W, Zhang, Q X, Chen, J D, Han, Z X, Liu, X, Feng, L, Shao. Y H, Rong, JG, Tong, G Z. Genetic diversity of avian infectious bronchitis strains isolated in China between 1995 and 2004. Archives of Virology 2006; 151:1133-1148.

Masters PS. The molecular biology of coronaviruses. Advances in Virus Research 2006; 66:193-292.

Mase M, Tsukamoto K, Imai K, Yamaguchi S. Phylogenetic analysis of avian infectious bronchitis virus strains isolated in Japan. Archives of Virology 2004; 149:2069-2078.

McKinley ET, Hilt DA, Jackwood MW. Avian coronavirus infectious bronchitis attenuated live vaccines undergo selection of subpopulations and mutations following vaccination. Vaccine 2008; 26:1274-1284.

Montassier MFS, Brentano L, Richtzenhain LJ, Montassier, HJ. Genetic diversity on $\mathrm{S} 1$ glycoprotein of avian infectious bronchitis virus strains isolated in Brazil between 1988-2000. Proceedings of the 5th International Symposium on Avian Coronavirus; 2006; Rauischholzhausen. Germany. v.1, p.119-131.

Montassier MFS, Brentano L, Montassier HJ, Richtzenhain LJ. Genetic grouping of avian infectious bronchitis virus isolated in Brazil based on RT-PCR/RFLP analysis of the S1 gene. Pesquisa Veterinária Brasileira 2008; 28:190-194.

Moore KM, Jackwood MW, Hilt DA. Identification of amino acids involved in a serotype and neutralization specific epitope within the S1 subunit of avian infectious bronchitis virus. Archives of Virology 1997; 142:2249-2256.

Moya A, Holmes E C, González-Candelas F. The population genetics and evolutionary epidemiology of RNA viruses. Nature Reviews Microbiology 2004; 2:279-288.

Nix WA, Troeber DS, Kingham BF, Keeler CLJ, Gelb JJ. Emergence of subtype strains of the Arkansas serotype of infectious bronchitis virus in Delmarva broiler chickens. Avian Disease 2000; 44:568581.

Pratelli A. Genetic evolution of canine coronavirus and recent advances in prophylaxis. Veterinary Research 2006; 37:191-200.

Rimondi A, Craig MI, Vagnozzi A; König G, Delamer M, Pered A. Molecular characterization of avian infectious bronchitis virus strains from outbreaks in Argentina (2001-2008). Avian Pathology 2009; 38:149-153.

Rowe CL, Baker SC, Nathan MJ, Sgro JY, Palmenberg AC, Fleming JO. Quasispecies development by high frequency RNA recombination during $\mathrm{MHV}$ persistence. Advances in Experimental Medicine Biology 1998; 440:759-765.

Seah JN, Yu L, Kwang J. Location of linear B-cell epitopes on infection bronchitis virus nucleocapsid protein. Veterinary Microbiology 
$2000 ; 75: 11-16$

Seo SH, Collisson EW. Specific cytotoxic T lymphocytes are involved in in vivo clearance of infectious bronchitis virus. Journal of Virology 1997; 71: 5173- 5177.

Seo SH, Wang L, Smith R, Collisson EW. The carboxyl-terminal 120residue polypeptide of infectious bronchitis virus nucleocapsid induces cytotoxic $T$ lymphocytes and protects chickens from acute infection. Journal of Virology 1997; 71:7889-7894.

Vijaykrishna D, Smith GJ, Zhang JX, Peiris JS, Chen H, Guan Y. Evolutionary insights into the ecology of coronaviruses. Journal of Virology 2007; 81:4012-4020.

Villarreal LYB, Brandão PE, Chacón JL, Assayag MS, Maiorka PC, Raffi ABS, Saidenberg ABS, Jones RC, Ferreira AJP. Orchitis in Roosters with Reduced Fertility Associated with Avian Infectious Bronchitis Virus and Avian Metapneumovirus Infections. Avian Diseases 2007; 51:900-904.

Villarreal LYB, Brandão PE, Chacón JL, Saidenberg ABS, Assayag MS, Jones RC, Ferreira AJP. Molecular Characterization of Infectious Bronchitis Virus Strains Isolated from the Enteric Contents of Brazilian Laying Hens and Broilers. Avian Diseases 2007; 51:974978.

Wang L, Junker D, Collission EW. Evidence of natural recombination within the S1 gene of infectious bronchitis virus. Virology 1993; 192:710-716.

Wang L, Junker D, Hock L, Ebiary E, Collission EW. Evolutionary implication of genetic variations in the $\mathrm{S} 1$ gene of infectious bronchitis virus. Virus Research 1994; 34:327-338.

Wang $\mathrm{C}-\mathrm{H}$, Huang $\mathrm{Y}-\mathrm{C}$. Relationship between serotypes and genotypes based on the hypervariable region of the $\mathrm{S} 1$ gene of infectious bronchitis virus. Archives of Virology 2000; 145:291300.

Williams AK, Wang L, Sneed LW, Collison EW. Comparative analysis of the nucleocapsid genes of several strains of infectious bronchitis viruses and other coronaviruses. Virus Research 1992; 25:213-222.

Woo PCY, Lau SKP, Huang Y, Yuen K-Y. Coronavirus diversity, phylogeny and interspecies jumping. Experimental Biology and Medicine 2009; 234:1117-1127.

Yu L, Wang Z, Jiang Y, Low S, Kwang J. Molecular epidemiology of infectious bronchitis virus isolates from China and Southeast Asia. Avian Disease 2001; 45:201-209. 